\title{
The future of farming for Southland
}

\author{
Jeff GRANT* \\ Chair Thriving Southland, The Plantations, 64 Pahiwi Balfour Road, RD6 Gore 9776
}

The future of Agriculture in Southland is facing another period of uncertainty, with the impact of covid19 and its possible long-term effects not fully. However, some indications are available regarding changing food patterns, disruptive shipping routes and the logistics of 'just in time' delivery that are being tested, border requirements changing and continuing disruptive technology changing the way consumers purchase all forms of consumable goods including food. This same uncertainty applies to the rest of New Zealand agriculture. The arable, Dairy, beef, sheep, and deer sectors are all trying to work through and prepare for what this uncertain future may look like, and how it will shape the future viability of farming enterprises.

\section{The Past}

The wider farming sector in Southland has faced the daunting task of new challenges before, and have adapted each time to emerge a more vibrant and stronger industry. In recent farming history, starting back in the early seventies, there was the introduction of various government incentives and subsidies in reaction to the risk of economic viability, and the farming industry reacted by developing more land, piling on fertiliser and increasing stock numbers, only to discover this was a false hope, as the markets had not been found for this increase, and so commodity subsidies were introduced.

The next wave was the mid-eighties, with the abrupt removal of farm subsidies both on commodity payments and inputs to the farm. This was followed by the restructure of the economy with the removal of tariffs on imports as well as the restructure of capital and the labour market. NZ agriculture bore the brunt of this change, with reform of the economy taking some years to complete. Freeing up access to market with other countries had some way to go, with the GATT round not opening world markets as promised. Agriculture went through a long period of low prices and difficult market conditions, including restrictions on some markets with high tariffs and non-tariff barriers. However, a gradual increase in commodity prices started to happen by the mid-nineties and the real gain for farmers came from productivity improvements on a massive scale across all sectors. Farmers had, once again, adapted well.

The late nineties saw the Global Financial Crisis (GFC) and, again, this bought challenges to agricultural production, with a contraction in consumer spending, which bought less rigor in standards and opened the supply from competitors, introducing cheaper products from the international market. The caused a response in New Zealand export entities to develop new products, improve logistics and develop a more direct route to both wholesale and retail in international markets. Each of these events have affected productivity and the capacity to supply the product the consumer is looking for within their discretionary spend.

\section{The Next Challenge}

The new challenge in the next two decades is fast approaching, and this could have a bigger impact on the farm level right through the supply chain, the unknown being possibly bigger than seen in previous periods. New Zealand, like many countries around the world, is endeavouring to tackle climate change impact and to become carbon neutral by 2050. In Southland, farming is a big part of the economy and its downstream industries are collectively the largest employer in the region. This brings with it the risk that 'not getting it right' will have long-term impact on the future prosperity for the local economy. Alongside this are public policy changes

- National Policy Statement for Freshwater Management 2020

- National Environmental Standards for Freshwater

- Biodiversity Strategy 2020 currently delayed.

- Re design of the RMA

Following on are the various regulations and policy implications that are or about to be enforced

- Stock exclusion regulations

- Mandatory and enforceable nitrogen fertiliser sales

- Winter grazing practices - sowing date, slope rule

- Restrictions on intensive winter grazing

- Restrictions on changes of land use

- Limit on synthetic nitrogen fertiliser

- Management of Critical Source Areas

- Animal welfare requirements

The above list has created an environment where there is confusion about implementation and timeframe for this to happen. Complexity has been created around how each of these ublic polices will be implemented, and whether regulations can or may be intertwined and not be stand alone in silos. This is causing uncertainty which then may develop into "stranded capital" which is where farmers invest in something, only to find the rules then change or the impact of the investment does not give the desired outcome. As an example, building a wintering barn to meet an obligation to reduce impact 
on freshwater quality, to find that, under another policy, the barn may have an adverse impact.

It is important for farmers to be given the knowledge and appropriate tools to make the right decisions. This is where Thriving Southland is endeavouring to play a part in assisting farmers in understanding what they can do in practical ways to make improvements that benefit both the farming enterprise and the surrounding environment,

\section{Thriving Southland role in the next challenge}

In Southland, like other regions, several community groups have been established over the last ten years around local water catchments which have taken an interest in learning about improving water quality. In the past, this had been supported by organisations such as Landcare Trust and local community driven groups. Increasing interest in a more co-ordinated approach saw a group of individuals establish Thriving Southland. The concept was developed with a board made up farmers and Agri businesspeople across the region. A major driver in the organisation is a 'ground up' approach, and many of the ideas and projects have come out of the Catchment Groups. Thriving Southland is about providing the 'tools not the rules', and, on that basis, tends to keep out of the political debate and would rather look for solutions to meet the regulations and policy directives.

Thriving Southland has a Project Leader, Project Manager and four Community Group Field Officers which are dedicated to the four main catchment areas as their primary responsibility, supporting activities and projects. On establishment, the group applied for a 3 -year funding grant from MPI, and the organisation has just completed its first year at the end of June $30^{\text {th }}, 2021$. Thriving Southland provides funding for a range of activities which are predominantly grassroots driven out of the catchment groups. There are now 28 catchment groups with over 1000 farmers interacting through field days, research, seminars, and education programs.

In the first year of operation, Thriving Southland have approved 39 grants for funding through an independent panel process, which has given many of the catchment groups the tools to enable individual projects to progress in their area. Thriving Southland has been active in the Southland winter grazing discussion, which is about developing better practices which will give farmers tools to meet future guidelines that will take effect in November 2022. This has included assisting with workshops, planning guides and information material on the key issues. Overall, farmers are making marked improvements in this area, but there is some way to go. What we have learnt is, if you explain the problem in order to create better understanding by giving information about good practice, farmers will adapt to get a beneficial outcome.
Environment Southland (regional council) have historically defined Southland into five catchment areas. Thriving Southland operate in four of these zones. (Fiordland national park being the only area excluded), covering $90 \%$ of the productive area. The four main catchment areas covered include the main rivers of Waiau, Aparima, Oreti and Mataur,a including their tributaries, of which Makawera is a major one.

Over the last two years, these groups have actively increased 'boots on the ground' with involvement by farmers and the wider community. A good example of this is the largest catchment group program funded so far.

\section{ACE project}

The Aparima Community Environment, known as the ACE project, is made up of six catchment groups along the Aparima river. This project has four workstreams.

1) Stream walks and water testing

2) Good farming practices

3) Sediment traps

4) Exploring future solutions

The biggest interest has been river and stream walks, which often see wider community involvement. This activity has generated high interest in wanting to understand the complexity of the waterways, impacts on the river and how to improve the quality of water. During each stream walk a SHMAK kit will be used to complete a Rapid Habitat Assessment which monitors macro invertebrates and riparian conditions and offers a chance to see an eDNA test in use. This will allow landholders to identify areas of good waterway management and areas where there is a room for improvement.

\section{Land and water Science Project Landscape DNA}

The next large project that Thriving Southland has secured funding for is in the wider Mataura River catchment for developing a better understanding of the topography and landscape of farms, and their impact on climate change and water quality. This project is building on work that has been carried out by Land and Water Science NZ, an Invercargill based Science and Consultancy business run by Dr Clint Rissmann. Land and Water Science are doing work across New Zealand. This is in collaboration and commercially with MIBIE, MPI, DOC and Crown Research Institutions, National Science Challenge, regional councils, and a range of industry and commercial agri-sector organisations. The project uses current high resolution and temporal data, ground truthing and developing mitigation to give farmers the right information to make decisions about appropriate land use. This work is multi-faceted and involves range layered data sets. When put together, this will give a real and scientific understanding of what 
is under your farm's topsoil, where the critical source points are and which areas have the biggest impact on such things as nutrient loss, pugging and leaching,

The fundamental background to the physiographic approach is that water quality outcomes vary spatially across the landscape, even when there are similar land use pressures. These differences are often the result of natural spatial variation in the landscape, which alters the composition of the water through coupled physical, chemical and biological processes. This work is being funded by AGMARDT grant and is, in my view, frontier stuff using the best technology and information available and putting it into a format that can be easily used by farmers, decision makers and regulators. The principle behind much of it comes, ironically, from the mineral industry, using radiography data as the base. This project has the potential to provide the 'Landscape DNA' at a paddock level and could provide the foundation for any environmental farm plans required in the future. Landscape DNA is the term given to the tools provided from the work that Land and Water have been developing for this fingerprinting tool. This will identify landscape factors governing water quality and soil GHG outputs, and is fundamental to informed investment decisions at catchment scaling up to the paddock level. The fingerprinting tool will utilise physiographic, land use and terrestrial biodiversity datasets to identify landscape factors governing risk and opportunity at catchment, property and paddock level. This is possible, as each layer within Landscape DNA is comprised of a numeric score of the environmental processes governing water quality and soil GHG outputs. Drawing a catchment, property or block boundary provides a means to quantify the inherent risk or opportunity in the area, including the ability to benchmark with other catchments, properties, blocks or even enterprise types.

The tool will provide a visual fingerprint of any given catchment or farm system, based on aggregated landscape data. When integrated with terrestrial biodiversity, farm nutrient and GHG budgeting tools, it is possible to provide a rapid diagnostic snapshot of the ecosystem services provided by the landscape. From here, the balance, or lack thereof, between the landscape setting and farm systems is readily apparent, especially when nutrient and GHG models for farm systems are provided. The ability to visualise the fit between farm systems and landscape is considered critical to any attempt to make meaningful change.

\section{The future challenge: is environmental sustainability a market export winner?}

For New Zealand agriculture the question is whether we can make the most of the increasing challenge that the impact of production has on the environment, or seek to stubbornly go along fighting any change in the hope someone will listen. Whether we agree or not, the debate on how to make the world more sustainable is here to stay and this will increasingly be driven by a new generation. Currently the millennials are writing the script and Generation $\mathrm{Z}$ will push for its delivery. My view is that, within this challenge, there is an opportunity to position $\mathrm{NZ}$ well for the future.

There are four components that need to be considered and addressed to position agriculture and its products to an increasingly informed and discerning consumer.

\section{The regulator}

To reshape the environmental outcomes, it is critical for the regulator not to overburden the regulatory aspect to the point of stopping innovation and compliance. There needs to be a clear pathway that is science based and credible to get buy-in from practitioners. The regulator plays an important role in verifying the integrity of an enhanced footprint in the environment. This is critical for the international markets and credibility of meeting standards has a big impact on how an importing country view our exports. New Zealand is a world leader in this area and respected for achieving what we say we will do.

\section{The consumer}

I am of the view that the consumer will decide ahead of the regulator of what they will purchase and from where, and so the pressure to change may come quicker than we realise. A lot of this is strongly based on perception and some based on science. The market will judge rightly or wrongly about the sensitivities of food production and what impact it has on the environment. As producers and exporters, we must deal with it. The challenge will see ever increasing discerning decisions being made by consumers, and their purchasing power.

\section{The risk}

The future risk created by not meeting environmental improvements to meet climate change international commitments and our national policy agenda on land and water will see the consumer judge our produce accordingly. This will require a 'holding of hands' between the regulator and the exporter in ensuring we do not lag behind in expectations offshore and that New Zealand is seen as a preferred supplier. This area requires more scientific research to counteract consumer perception. Increasingly, I have found when you argue a position based on science with the lawmaker's policy advisors in any international market, you reduce the risk of unworkable standards which can impact exports.

\section{The opportunity}

Increasingly, international pressure is affecting food production, and its cost to the environment. Firstly, New Zealand has proven to date that we can meet this 
challenge, as seen in the progress made in understanding the issues and looking for solutions to reduce the impact from our farms. New Zealand is not a laggard, as some would claim, in fact implementation of a range of waterway protection strategies, alternative crop use and implantation of sustainable practices is way ahead of other country around the world. Many countries have the regulations but not the success of implementation.

Government, producers and exporters need to understand and seek out the key aspects where we are successful for future messaging as the next generation of consumers, which are continually looking at how food is produced. New Zealand has the best opportunity of any exporting country in the world to turn this challenge of our future environmental impact as a nation into a strong selling story for exports.

New Zealand produces food as a vast range of highquality products that feed approximately 40 million people around the world. Collectively, over the last 40 years, the agriculture industry has endeavoured to push up the value chain for our products, and have done so with some success. The ability to enhance that position by best environmental practice will, in my view, give New Zealand the opportunity to take the next step.

Disruptive technology is starting to change the way the food market will operate over the next ten years and the market we need to keep chasing is for the discerning consumer in the high income/high worth groups. Changes in the supply line and distribution, along with more direct links from blockchain type mechanisms will see increasingly stronger links between the source of food and the consumer. The big driver for this group in purchasing food is their increasing emphasis on its impact on the environment along with animal welfare. This group do not buy on price, but do accept paying a premium in the knowledge they are doing the right thing.

I am of the view if we get this right, we will see $\mathrm{NZ}$ exports capturing more of the benefit over the next twenty years, before facing the next significant challenge of protein alternatives. 